\title{
Uma leitura de "A escrava branca" e "Intimidade", de Daniel Galera, sob a luz das teorias do conto
}

\author{
Flávio Amorim da Rocha \\ Universidade Federal de Mato Grosso do Sul (UFMS), \\ Campo Grande, Mato Grosso do Sul, Brasil \\ flavio.rocha@ifms.edu.br
}

DOI: http://dx.doi.org/10.21165/el.v46i3.1600

\begin{abstract}
Resumo
O presente trabalho tem por objetivo apresentar uma leitura de dois contos de Daniel Galera: "A Escrava Branca" e "Intimidade", publicados em Dentes Guardados, primeiro livro do escritor. As narrativas, que descrevem relacionamentos por conveniência, apresentam o homem no centro do caos, em busca de algo que talvez nem ele próprio saiba o que é, absorto em suas ocupações cotidianas. O percurso escolhido para esse fim parte da apresentação das contribuições teóricas de estudiosos do gênero conto, tais como Poe, Hemingway, Piglia e Cortázar, a fim de que se possa observar como elas auxiliam na construção de sentido dos textos contemporâneos.
\end{abstract}

Palavras-chave: teorias do conto; literatura contemporânea; Daniel Galera.

\section{Reading "A escrava branca" and "Intimidade" by Daniel Galera through short story theories}

\begin{abstract}
This paper aims at analyzing two short stories written by Daniel Galera: "A escrava branca" and "Intimidade", published in the writer's first book Dentes Guardados. The short stories, which approach relationships of convenience, show human beings in the center of chaos searching for something that maybe they do not even know what it is as they are so involved in their daily occupations. The path chosen for this analysis starts with theoretical contributions from studies about short stories carried out by writers such as Poe, Hemingway, Piglia and Cortázar. These theories are used in this article in order to observe how they can be important to the interpretation process of contemporary texts.
\end{abstract}

Keywords: short story theories; contemporary literature; Daniel Galera.

\section{Introdução}

Este artigo tem por objetivo realizar uma leitura dos contos "A escrava branca" e "Intimidade", de Daniel Galera, escritor brasileiro contemporâneo. Pretendemos, para isso, estabelecer diálogos entre os elementos narrativos dos contos e os pressupostos teóricos de autores como Poe, Tchekhov, Hemingway e Cortázar, expoentes, cada qual em seu tempo e a seu modo, da arte de construir histórias curtas. Apresentaremos, portanto, as principais contribuições desses escritores, de forma breve. Após a contextualização histórica do conto, passaremos à análise do corpus.

Para que se possa propor qualquer estudo sobre o conto enquanto gênero literário, parece-nos necessário citar as contribuições dos grandes autores que se dedicaram ao ofício da economia de palavras e da maximização das sensações transmitidas ao leitor, características fundamentais para que um conto seja considerado bem-sucedido. Devido, 
principalmente, à sua extensão e objetividade, o conto é o gênero que representa a sociedade contemporânea em sua fragmentação e nas experiências intensas de busca por uma identidade do homem pós-moderno que, por sua vez, tem cada vez menos tempo para ler textos extensos.

É possível perceber, nesse cenário, que há uma forte tendência de contistas contemporâneos a retratar a efemeridade das relações sociais e a objetificação do homem. Questiona-se a velocidade com que as coisas acontecem, a aparente proximidade gerada pelos meios de comunicação e, em oposição a isso, o distanciamento das pessoas e o papel que a interação entre elas exerce na constituição do ser humano que vive essas transformações.

Por sua vez, o leitor da atualidade, inserido nesse contexto, quando lê, tende a procurar histórias concisas, que possam ser lidas no intervalo entre um turno de trabalho e outro ou no curto tempo do qual dispõe antes de dormir. O conto mostra-se, dessa forma, gênero ideal para que o leitor mantenha o contato com a literatura e para que a leitura literária seja encorajada. São inúmeros os contistas que transformam um número limitado de páginas e caracteres em obras que transcendem a materialidade e abordam as grandes questões humanas que têm sido retratadas pela literatura desde os primórdios da civilização.

A literatura brasileira contemporânea conta com grandes nomes que se debruçam sobre a arte de escrever contos. Esses autores, no entanto, são heranças de uma tradição literária que remonta às primeiras narrativas humanas, que fazem parte da história da civilização. Dialogam, portanto, com os grandes contistas que surgiram ao longo do tempo e esses diálogos podem ser evidenciados e, consequentemente, podem auxiliar no processo interpretativo das narrativas atuais.

Apresentamos neste trabalho contos do escritor Daniel Galera, nascido em São Paulo, em 1979, mas criado em Porto Alegre. Galera já publicou seis livros e neste ano de 2016 publicará o sétimo. As temáticas abordadas em suas obras, contos e romances, parecem convergir para um pano de fundo comum: o homem em sua eterna solidão à procura de si próprio. $\mathrm{O}$ sujeito aparece quase sempre deslocado, possui uma consciência crítica, mas é muitas vezes impedido de agir por conta do contexto social em que vive. Procura, portanto, um espaço para ouvir sua própria voz e depara-se com questionamentos que tomam gigantescas proporções.

Antes de adentramos seus contos com a análise proposta, gostaríamos de tratar brevemente de alguns aspectos teóricos relevantes para o percurso que seguiremos na análise dos dois contos da obra Dentes Guardados.

\section{O conto: contribuições teóricas}

$\mathrm{O}$ ato de narrar histórias faz parte da herança cultural do homem. Antes mesmo da invenção da escrita, a tradição oral, repassada de gerações em gerações, era responsável por registrar importantes eventos e feitos da civilização. A fuga da realidade, por meio da criação de universos fantásticos e repletos de imaginação, torna-se uma necessidade e é responsável por narrativas que remontam aos primórdios da existência humana. 
Dessa forma, parece-nos que a origem do conto, compreendido aqui segundo a definição de Edgar Allan Poe como narrativa curta que se pode ler de uma só vez, está na origem da indagação do homem sobre sua própria identidade. Temos, por exemplo, na Bíblia, um dos mais antigos livros da nossa cultura, diversas histórias narradas de diferentes pontos de vista, como, por exemplo, o Gênesis, que nos apresenta uma teoria sobre a criação do mundo, e as parábolas, episódios sobre a vida de Cristo na terra, com finais moralizantes e doutrinadores. Assim como na Bíblia, há nos mitos gregos similar urgência em explicar aquilo que não se compreende, traduzida em contos que povoam o imaginário da humanidade e buscam dar sentido à vida.

Sendo, portanto, uma das mais antigas formas de se narrar uma história e de procurar compreender a existência humana, o conto suscita importantes discussões por parte de autores considerados expoentes da literatura mundial, como Edgar Allan Poe, precursor do conto moderno. Para o contista americano, essas narrativas são construídas já tendo em vista o seu desfecho. Além disso, o conto deve possuir um único tom escolhido pelo narrador e, diante desse tom, o léxico é cuidadosamente selecionado e as personagens são criadas tendo em mente o efeito de sentido que se pretende causar no leitor, peça fundamental para o processo de recepção de qualquer obra literária.

Poe, mestre das narrativas fantásticas, é um dos expoentes do conto de enredo, que tem nos acontecimentos e nas ações das personagens elementos importantes para a construção da história. Os contos de mistério de Edgar Allan Poe requerem fatos desencadeados de maneira inesperada para que o efeito por ele pretendido chegue até o leitor:

Nesse aspecto, tudo, no texto, é absolutamente importante. Ou como ele afirma, "se a primeira frase não se direciona ao resultado desse efeito, ele já fracassou em seu primeiro passo. Em toda a composição não deve haver uma palavra escrita cuja tendência, direta ou indireta, não leve àquele único plano preestabelecido" (KIEFER, 2004, p. 32).

Anton Tchekhov, a quem são atribuídos os créditos de precursor do conto de atmosfera, muito embora já possamos encontrar elementos desse tipo de conto em obras de Machado de Assis, o define como narrativas que giram em torno de acontecimentos banais na vida de pessoas comuns. Tem-se a sensação de que nada acontece e não há uma relação de causa e efeito, mas um estado psicológico da personagem que se revela durante a narrativa. As ações das personagens são, portanto, secundárias e cedem espaço a transformações que ocorrem no plano dos sentimentos.

$\mathrm{Na}$ literatura brasileira, Machado de Assis e Clarice Lispector trabalham com primor o conto de atmosfera. Se pensarmos, por exemplo, em Amor, de Clarice, percebemos a vida cotidiana de uma dona de casa sofrer a interferência de um momento de iluminação, marcado pela visão de um homem cego que mascava chiclete no ponto de ônibus. Esse homem leva a personagem a uma viagem interior repleta de questionamentos existenciais, descritos na maior parte do conto. Temos, assim, um episódio comum na vida de uma pessoa comum - uma dona de casa vai às compras e pega um bonde. Mas a visão do homem cego direciona a narrativa para a introspecção e o desencadeamento de reflexões psicológicas até que tudo volte ao seu devido lugar.

No século XX, a prosa passa por um momento de transformação, no qual fala-se, inclusive, na morte do romance. Nesse cenário, surge Ulysses, de James Joyce. O irlandês introduz uma novidade no conto: a narrativa já não segue mais a noção de enredo de Poe 
e atualiza a noção que se tinha de conto de atmosfera. Os efeitos de sentido são, em Joyce, gerados pelos momentos de epifania, de revelações importantes que modificam a vida da personagem. Ao contrário do que acontece em Lispector, se Joyce houvesse escrito Amor, a dona de casa não sairia ilesa da experiência com o cego. Haveria mudanças significativas para a história da personagem.

As narrativas intimistas do conto de atmosfera têm ainda em Virginia Woolf e Katherine Mansfield importantes representantes. Suas histórias tendem a eliminar os pequenos acontecimentos e focar, de maneira intensa, os conflitos interiores das personagens. Percebemos esse recurso no conto "A marca na parede", de Woolf. A história retrata uma mulher que indaga o que seria uma certa marca na parede que está à sua frente. Não há um percurso de ações e o cenário único é a sala de estar dessa personagem. O conto todo apresenta um permanente fluxo de consciência, retratando as conjecturas da mulher a respeito do que poderia ter resultado naquela mancha que a incomoda, mas, ao mesmo tempo, a impede de levantar-se para averiguar do que se trata.

Júlio Cortázar, no texto 'Do conto breve e seus arredores', pontua a importância de se contar a narrativa como se ela tivesse interesse apenas para o ambiente restrito das personagens. Esse ambiente pequeno, do qual o narrador vem a fazer parte, retoma a ideia de forma fechada do conto, sua esfericidade, causando no leitor a sensação de que está lendo algo que nasceu por si mesmo. A presença do demiurgo não é marcada na história. Os recursos do diálogo e das narrativas em primeira pessoa são importantes para construir essa noção de fechamento do conto, de pertencimento e significação para a diegese. A experiência do leitor não é, na maioria das vezes, mediada por uma voz que interfere nos acontecimentos.

Ernest Hemingway faz sua contribuição com a teoria do iceberg que sugere que apenas um oitavo do conto encontra-se na superfície; o resto está submerso. Cabe ao leitor descobrir as partes da narrativa que não são visíveis em uma leitura superficial, mas detectáveis por meio da escolha lexical do autor. Para o norte-americano, aquilo que se enxerga na história recebe suporte de diversos elementos que são apenas inferidos a partir da narrativa. A história então contada em poucas palavras traz à tona múltiplas significações que podem ser encontradas pelo leitor se ele souber seguir as pistas deixadas pelo narrador ao longo do conto.

Ricardo Piglia, a exemplo de Hemingway, acredita que há mais nos contos do que aquilo que está escrito. Para ele, todo conto conta duas histórias, ou seja, há uma evidente e outra secreta que pode ser identificada pelo leitor por meio dos mecanismos de construção da narrativa. O teórico vê em Kafka um exemplo de conto escrito pelo contrário. Em "A Metamorfose", por exemplo, a narrativa é iniciada pela transformação da personagem principal em um inseto e suas sensações decorrentes dessa mutação. Há, no entanto, submersa ou secreta, a história que guia a personagem até o momento inicial da narrativa, há acontecimentos que fizeram com que essa alegoria do inseto fosse utilizada pelo autor. Esses acontecimentos estão inseridos, segundo Piglia, em uma segunda história.

Esboçamos aqui um panorama muito breve dos principais conceitos acerca do gênero conto, os quais nos propomos a utilizar como ferramenta da leitura dos contos selecionados. Buscaremos relacioná-los à escrita contemporânea de Daniel Galera a fim de observar a presença dessa tradição em textos que representam o homem atual em 
constante crise individual diante dos conhecimentos cada vez mais compartimentados sobre a realidade em que vive.

\section{Daniel Galera e as tendências do conto contemporâneo}

Os contos "A escrava branca" e "Intimidade" fazem parte da obra Dentes Guardados, lançada pelo autor em 2001, mas que reúne histórias publicadas na internet desde 1997. As 1100 tiragens do livro estão esgotadas e, desde então, Galera disponibiliza o livro para download gratuito em sua página na internet. A coletânea apresenta 14 contos que têm como eixo comum cenas da vida cotidiana permeadas por incidentes que desencadeiam no leitor efeitos de surpresa diante de textos construídos, em sua maioria, por meio de diálogos e por uma linguagem bastante coloquial, responsável pela aproximação entre a narrativa e seus receptores. Galera, a exemplo de autores como Luiz Vilela e Sérgio Sant'Anna, mostra uma técnica apurada na construção desses diálogos, que, ao representar marcas de linguagem das personagens, conferem ao texto efeitos importantes de verossimilhança.

O narrador em primeira pessoa de "A escrava branca" inicia o conto causando estranhamento no leitor ao relatar: "Decidi que o que eu precisava era de uma escrava branca. Botei um anúncio no jornal" (GALERA, 2002, p. 50). No decorrer da narrativa, é possível observar que, para a sociedade do conto de Galera, a procura por tais serviços é algo rotineiro. Os amigos do narrador protagonista afirmam que "Em geral, relações com escravas brancas começam bem mas tornam-se rapidamente problemáticas" e o próprio narrador conclui: "As escravas brancas estão desacreditadas em nosso tempo" (GALERA, 2002, p. 53).

Percebemos que a mulher desejada para os serviços é tratada como um objeto, uma mercadoria. Há os requisitos bem delimitados para sua aquisição: ser magra, levemente fornida, possuir uma coluna vertebral ótima e apresentar nível cultural mediano ou elevado. O padrão de beleza estipulado pela sociedade contemporânea é representado nas exigências do demandante. Podemos notar, também, condições para que se firme o contrato: a presença permanente em casa, os favores sexuais irrestritos e exclusivos ao dono.

No momento da entrevista com Elise, a escrava, o narrador faz uma avaliação do produto: peitos bons, bunda boa e coluna de acordo com o exigido: "Pedi pra ela tirar a roupa para eu dar uma conferida. Magra mas recheada nos pontos ideais, espáduas vigorosas, ombros elevados, boa proporção de troncos e membros" (GALERA, 2002, p. 51).

Notamos nos diálogos entre contratante e contratada o pragmatismo próprio da sociedade contemporânea, além da efemeridade e superficialidade das relações humanas diante dos compromissos cotidianos com o trabalho, com a busca pelo sucesso e pela sobrevivência nas selvas de pedra onde habita o homem do século XXI. A frieza com que é descrita a cena do primeiro contato entre o narrador e Elise desconcerta ao afirmar esse relacionamento por conveniência, além da superioridade do homem que exige e a subserviência da mulher que aceita suas condições.

À medida em que a convivência se torna rotineira, o narrador surpreende-se ao notar que começa a sentir afeto por Elise. A necessidade de aproximar-se dela é a grande surpresa do conto. Marcas do sentimento do narrador são deixadas pouco a pouco no 
texto. Inicialmente, ele se decepciona quando ela afirma não sentir falta de sair de casa e de ter amigos, atividades proibidas no contrato firmado entre os dois. Ao observar que seu sentimento parece fora de controle, consegue, inclusive, diferenciar Elise dos escravos: "Escravos são objetos. Ela era mais do que um objeto. Eu estimava ela" (GALERA, 2002, p. 55).

A "adorável submissão" da escrava branca passa a desanimar seu dono a tal ponto que desencadeia uma importante transformação na narrativa: "Agora eu queria que ela fosse parte da minha vida. Chorei uma noite inteira depois desse pensamento. Eu estava amando" (GALERA, 2002, p. 56). Os papéis estão agora invertidos. O controle passa a ser de Elise quando o narrador demonstra o medo de conversar com ela sobre seus sentimentos. Percebemos claramente que o narrador teme aproximar-se dela e ser rejeitado. Um passo como esse o tiraria da posição de poder adquirida no início da narrativa quando ele coloca o anúncio no jornal.

Quando, finalmente, toma coragem para confessar a Elise seu amor, a reação da personagem surpreende o leitor: ela se sente traída com relação ao combinado inicial, demonstra seu desconforto e afirma não querer as coisas de forma diferente e despede-se de seu patrão com um beijo na testa.

Já no conto "Intimidade", o narrador surge no início da narrativa indignado por ter encontrado um pedaço de alface em sua escova de dentes e briga com a namorada, Linda, por isso. A relação entre os dois é, como em "A escrava branca", uma união por conveniência: "Ela dorme no meu apartamento nos fins-de-semana e às vezes aparece também nos dias úteis pra comer minha comida, beber minha cerveja e dormir abraçadinha comigo. Somos como todo mundo, precisamos disso de vez em quando" (GALERA, 2002, p. 15).

Também neste conto percebemos o conformismo na relação a dois. Estão juntos quando lhes convém e a intimidade forçada pelo uso da mesma escova de dentes assusta o narrador a ponto de levá-lo a desferir um tapa na cara da companheira ocasional. Linda chora e não se sabe se o choro é pelo tapa ou pela sua tentativa frustrada de uma maior aproximação do homem. Ele percebe ter exagerado e demonstra um controle subentendido de Linda quando afirma que ela sabia que ele pediria perdão e se arrependeria de tê-la agredido. Compreendemos, portanto, não ser essa a primeira vez que o casal se envolve em um episódio de violência.

O narrador reconhece que foi longe demais e que a demonstração de intimidade era importante para Linda. Ela parece ceder após o tapa e concordar com a ideia da relação superficial. Quando o companheiro começa a acariciá-la, ela liga o walkman e conta uma história a respeito de seu irmão durante toda a relação sexual. Ao responder dessa forma, ela aceita as condições impostas pela postura do narrador no início do conto e, embora sofra, afinal é encontrada bêbada em casa após desaparecer do cinema, com marcas visíveis de ter chorado muito, aceita o contrato de conveniência: passa na farmácia e compra 28 escovas de dente.

Percebemos, em ambos os contos, a fragilidade das relações humanas e a busca pela compreensão de si próprio por meio da identificação com o outro. Os papéis se invertem nas histórias - o aparente dominador questiona-se, parece mudar de opinião, mas é surpreendido quando a resposta da parceira é a aceitação de uma ideia inicial que, tanto em "A escrava branca" quanto em "Intimidade", se resume no relacionamento por 
conveniência, superficial, sem grandes envolvimentos e compromissos assumidos em nome de um sentimento mais profundo.

O homem é colocado por Daniel Galera no centro do caos contemporâneo, na busca por algo que nem ele conseguiu ainda definir o que é e, para tal, ocupa-se das pessoas como se elas fossem apenas mais uma tarefa em seus compromissos diários. Das outras pessoas utiliza-se apenas o que convém para que as necessidades imprescindíveis, como o sexo, sejam satisfeitas.

Há, no entanto, um anseio por algo que esteja além dos contratos sociais plenamente vivenciados pelo homem do século XXI. Um certo desconforto parece ser revelado nos contos de Dentes Guardados e pode ser vislumbrado nas histórias aqui tratadas. Parece-nos que o desejo por uma conexão mais íntima com o ser humano ainda existe, mas que isso é sempre negado aos que estão dispostos a persegui-la. Estaria o homem contemporâneo fadado à superficialidade das relações com o próximo? A angústia suscitada por esse pensamento traduz-se nos gritos que ecoam nesses contos magistralmente construídos pelo jovem escritor.

\section{O conto de Galera e a tradição}

Antonio Carlos Viana (2010), ao tratar do conto brasileiro hoje, afirma acreditar que os estudos da literatura deveriam ter início com os escritores contemporâneos e, partindo deles, trilhar o caminho para o passado, resgatando as contribuições da tradição e observando como elas dialogam com o fazer artístico no presente. Esse é o caminho que escolhemos percorrer para estabelecer conexões entre os contos de Daniel Galera e grandes nomes da literatura mundial. É possível notar que, enquanto leitores do grande cânone, esses autores contemporâneos utilizam-se de técnicas que são atualizadas e transformam-se em características peculiares do escritor.

O mesmo Viana propõe uma classificação de novos autores de acordo com a herança literária presente em seus textos. Nesse sentido, ele coloca Galera em uma tradição que tem como um de seus grandes representantes João Ubaldo Ribeiro e Mário de Andrade. O que esses autores têm em comum é o trabalho com a linguagem mais coloquial, com as marcas discursivas da oralidade em seus textos. Galera é, para Viana, em Dentes Guardados, um escritor "dono de uma linguagem ágil, moderna, sem medo algum das palavras" (VIANA, 2010, p. 280).

Vimos, anteriormente, que, para Edgar Allan Poe, a escolha cuidadosa das palavras pelo autor é responsável pelo efeito de sentido que se pretende causar no conto. Para Hemingway, esse léxico é imprescindível para que se recupere a parte do iceberg que se encontra submersa. Diante desses preceitos, encontramos em Daniel Galera um intenso trabalho técnico para representar em seus contos aqui analisados o homem contemporâneo, causando no leitor, ao término da história, a sensação de pasmo diante das relações interpessoais.

Em "A escrava branca", a utilização de palavras e vocábulos como: escravidão, dotes, período de avaliação, contrato permanente, entrevista, patrão, hierarquia, negócio, mulher de estimação, devoção e servidão contribui para construir esse efeito de pasmo diante do absurdo da história. O leitor se depara, em pleno século XXI, com ideias retrógradas de dominação da mulher e machismo exacerbado. 
Já em "Intimidade", a descrição de sentimentos por meio de palavras e expressões, tais como: ofensa, ódio irracional, banalidade, orgulho, atos impensados e incredulidade, expressos na construção do conto, causam no leitor a mesma sensação que o conto anterior. Um homem perde a razão diante do fato de a mulher ter utilizado sua escova de dentes, torna-se agressivo e bate na companheira. Uma violência gratuita, sem aparente motivação, mas que encerra a chave para a compreensão de ambos os contos.

Se pensarmos na teoria do iceberg de Hemingway e na tese de que todo conto conta duas histórias, de Piglia, podemos, por meio de um estudo mais cuidadoso do texto, utilizando a construção lexical, cuja importância já havia sido pontuada por Poe, criar uma hipótese sobre qual história está sendo contada e qual está submersa, nas entrelinhas da escrita de Galera. Defendemos aqui que a segunda história é a mesma em ambos os contos.

"A escrava branca" trata de um episódio absurdo no qual um homem coloca um anúncio no jornal a fim de contratar uma mulher, com perfil bem delimitado, para ser sua serva sexual. Ele se apaixona por essa mulher e uma mudança importante acontece na narrativa: a objetificação de Elise não faz mais sentido para o narrador. Ele deseja agora que ela seja sua companheira oficial, pensa em pedi-la em namoro e em casamento. Tal mudança parece, inclusive, ter relação com o contato que Elise estabelece com a literatura.

Em um primeiro momento, a escrava discute com o narrador o conto "O Beijo", de Tchekhov. Ela incomoda-se com o personagem da narrativa que não tenta descobrir quem havia sido a moça que lhe tinha dado um beijo no escuro durante uma recepção para os soldados na casa de um importante homem da cidade. O narrador explica para Elise que a resposta para a sua indagação (o porquê de o soldado não ter ido procurar pela moça) está em cada leitor e reflete: "Testemunhar um conto de Tchekhov surtindo seu efeito numa escrava branca deve ser algo muito raro de acontecer. Ela estava compreendendo o conto" (GALERA, 2002, p. 54).

A menção a um dos maiores expoentes do conto universal não é gratuita. Galera, ao estabelecer esse importante diálogo com a narrativa do escritor russo, apresenta ao leitor as indagações de Elise quanto ao relacionamento amoroso. Sabe-se que em "O Beijo", o soldado guarda na memória sensações como o cheiro, o som do vestido da mulher e a textura de sua pele. Essas recordações são suficientes para que ele viva intensamente sua história de amor. Como se reconhecer a mulher que o beijara pudesse tirar todo o encanto de uma idealização pessoal.

De certa forma, Elise havia romanticamente idealizado sua relação com o protagonista do conto. Para ela, a submissão e a satisfação dos desejos dele eram elementos importantes para a concretização da sua história de amor. Contudo, ao lhe confessar seus sentimentos, logo após uma nova referência literária de Elise a Hilda Hilst, o narrador causa em sua interlocutora espanto: "Assim não funciona. Eu não quero. Acho melhor acabar com tudo antes que piore" (GALERA, 2002, p. 58). A primeira história do conto termina com a escrava indo embora e levando consigo a coletânea de contos de Tchekhov.

Em "Intimidade", a primeira história resume-se em uma briga de casal iniciada pela irritação do homem quando descobre que sua companheira ocasional havia utilizado sua escova de dentes. Há agressão física, pedidos de perdão e arrependimento. Logo após um ato sexual eles vão ao cinema para assistir a uma comédia americana. Ela abandona a 
sessão e ele sai à sua procura, para em um bar, bebe e volta para casa. Encontra a mulher deitada na cama, após ter tomado quase uma garrafa inteira de vodca, e percebe em cima do sofá um saco plástico de farmácia com 28 escovas de dente.

Em ambos os contos, acreditamos que a segunda história seja a mesma. Além das relações conturbadas entre os casais, constrói-se paralelamente uma narrativa sobre a busca pelo relacionamento com o outro. Essa busca reflete-se em uma crise de identidade do homem contemporâneo que, para Stuart Hall, não a possui mais de forma física, já não tem uma ancoragem ao mundo. Esse homem transforma-se constantemente a fim de adaptar-se às transformações da sociedade em que vive, assumindo identidades temporárias.

Tais adaptações explicam o pragmatismo da vida contemporânea. É preciso resolver os problemas do agora, momentâneos. A necessidade é sexual? Contrata-se uma escrava branca. A individualidade parece ameaçada? Tenta-se afastar os que procuram a proximidade. Assim, nos contos de Galera, temos a presença desse ser humano que questiona constantemente seu lugar no mundo. Ao mesmo tempo que deseja a proximidade do outro, não sabe lidar com ela, por medo, talvez, de que a alteridade possa revelar a ele coisas sobre si mesmo. Estaria, então, preparado para isso?

O narrador de "A escrava branca" surpreende-se com os sentimentos que são nele despertados. Deseja a convivência a dois, mas o contrato havia sido estipulado e a outra parte não cede. Para Elise, a concepção de relacionamento está condicionada à sua entrega incondicional. Para o protagonista de "Intimidade", o título do conto soa como algo inconcebível no início, mas ele reflete e sente-se enternecido pelo sofrimento da namorada. Ela, por sua vez, também aceita o pacto inicial: ao comprar as escovas de dente parece afirmar que esse distanciamento é necessário para que o relacionamento entre os dois funcione.

Portanto, a segunda história comum a ambos os contos é a busca incessante pelo contato com o outro: os encontros e os desencontros do desejo de estar junto, mas sem saber como agir para que isso aconteça. Esses elementos do conto aparecem também nos romances de Galera; o homem que ele retrata enfrenta dificuldades de se relacionar com o outro e permanece isolado em sua constante solidão.

\section{Considerações finais}

Pretendemos, com esse estudo, aproximar a construção de dois contos contemporâneos do escritor Daniel Galera, "A escrava branca" e "Intimidade", dos conceitos elaborados por escritores canônicos como Poe, Hemingway, Tchekhov e Cortázar acerca das narrativas curtas.

Observamos a presença de elementos destacados por esses grandes nomes da literatura universal nas narrativas do jovem autor. Os contos são construídos tendo em mente provocar um efeito único no leitor: o de pasmo diante das relações humanas interpessoais.

Há, nas histórias de Galera, evidências suficientes para que se possa afirmar a existência de uma segunda história comum aos dois contos aqui analisados: partindo de um episódio comum na vida de pessoas comuns, da forma como evidenciava Tchekhov, constrói-se uma narrativa paralela que tem por fio condutor a procura do homem pela sua 
identidade no contato com o outro e seu fracasso nesse intento, resultando na solidão contemporânea.

\section{REFERÊNCIAS}

CORTÁZAR, J. Do conto breve e seus arredores. In: . Valise de Cronópio. São Paulo: Perspectiva, 1974.

GALERA, D. Dentes guardados. Porto Alegre: Livros do Mal, 2002.

HALL, S. A identidade cultural na pós-modernidade. Tradução de Tadeu da Silva e Guacira Lopes Louro. 11. ed. Rio de Janeiro: DP\&A Editora, 2006.

KIEFER, C. A poética do conto. Porto Alegre: Nova Prova, 2004.

PIGLIA, R. Teses sobre o conto. In: . Formas breves. Tradução de José Marcos Mariani de Macedo. São Paulo: Cia das Letras, 2004.

POE, E. A. A filosofia da composição. In: Rio de Janeiro: Nova Aguilar, 1997. p. 911-920. . Ficção completa, poesia \& ensaios.

VIANA, A. C. O conto brasileiro hoje. In: Interdisciplinar: Revista de Estudos em Língua e Literatura, Universidade Federal de Sergipe, ano V, v. 11, p. 271-282, 2010. Disponível em: <http://www.seer.ufs.br/index.php/interdisciplinar/issue/view/136>. Acesso em: 21 ago. 2016.

Recebido em: 24/08/2016

Aprovado em: 20/01/2017 